\title{
O EFEITO "MATRIOSCA": DESVENDANDO AS ESPECIFICIDADES DOS GRUPOS UNIVERSAIS HIPERVULNERÁVEIS DE CONSUMIDORES NAS RELAÇÕES JURÍDICAS DE CONSUMO
}

Fernando Costa Azevedo* Lúcia Dal Molin Oliveira**

\begin{abstract}
RESUMO: O artigo propõe uma reflexão sobre a necessidade de se aprimorar a proteção do consumidor nas relações de consumo a partir de uma interpretação que, para além do importante reconhecimento das categorias universais do consumidor enquanto pessoa humana vulnerável e daquela situada em grupo social hipervulnerável, reconheça as especificidades que compõem o consumidor enquanto pessoa humana concreta, atendo-se para o contexto individual e social. A boneca russa "Matriosca" (Matryoshka) serve para representar o ato interpretativo que vai do mais universal (as condições vulneráveis e hipervulneráveis), para enfim chegar às especificidades da situação concreta pela pessoa humana consumidora.
\end{abstract}

PALAVRAS-CHAVE: Vulnerabilidade; Hipervulnerabilidade; Consumidores; Relação de Consumo.

\section{THE "MATRIOSHKA" EFFECT: UNVEILING THE SPECIFICITIES OF THE HYPERVULNERABLE UNIVERSAL GROUPS IN THE LEGAL CONSUMER RELATIONS}

\begin{abstract}
The article proposes a reflection on the need for improving the consumer protection in the consumer relations from an interpretation that, besides the important acknowledgment of consumer universal categories as a vulnerable human being and that one found in a hypervulnerable social group, it acknowledges the specificities that comprise the consumer as a concrete human person, responding to the individual and social context. The Russian doll "Matrioshka" serves to represents the interpretative act that ranges from the more universal (the vulnerable and hypervulnerable conditions), to finally reach the specificities of the concrete situation by the consumer human person.
\end{abstract}

KEYWORDS: Vulnerability; Hypervulnerability; Consumers; Consumer Relation.

\footnotetext{
* Doutor em Direito pela UFRGS. Mestre em Direito pela UFSC. Professor Adjunto da UFPel. E-mail: fecoaze@ig.com.br

** Mestranda em Direito pela UFPel. Especialista em Direito Empresarial pela UFRGS. Advogada. E-mail: luciadalmolin@gmail.com
} 
Fernando Costa Azevedo \& Lúcia Dal Molin Oliveira

\section{INTRODUÇÃO}

É conhecida de todos a tradicional boneca russa Matriosca (Matryoshka) que é, na verdade, um conjunto de bonecas que se encaixam uma dentro da outra até chegar à última que, ao contrário das outras, não é oca. No folclore russo a existência da boneca está associada a uma antiga lenda (CORDEIRO, 2018, p. 01), segundo a qual um carpinteiro chamado Serguei encontrou no bosque perto de sua casa um belíssimo tronco de madeira e, alguns dias depois, teve a inspiração de criar um brinquedo diferente, uma boneca. Ao finalizar sua obra afeiçoou-se de tal modo por ela que decidiu não vendê-la, mas ficar com a boneca em sua casa. Eis que lhe deu o nome de Matryoshka e começou a conversar diariamente com ela até que, num certo dia, escutou também a sua voz!

O tempo passou e Serguei notou, certa vez, que Matriosca estava triste. Perguntando a ela o que estava ocorrendo disse-lhe que se sentia sozinha e que gostaria de ter um filho ou filha. O carpinteiro, tomado de muita compaixão, disse que teria de abri-la e que seria doloroso fazê-lo. Em resposta, disse Matriosca: "na vida as coisas importantes requerem um pequeno sacrificio".

Essa pequena passagem da curiosa lenda ${ }^{1}$ reúne os elementos fundamentais para a proposta que pretendemos apresentar neste trabalho. Com efeito, o carpinteiro representa o jurista e o aplicador do direito assim como a boneca criada, a realidade que lhes revela - e da qual eles também produzem, por ato hermenêutico - o fenômeno jurídico. E o exercício da interpretação jurídica, sendo uma das "coisas importantes", requer igualmente um "pequeno sacrifício", como o de sair da superfície dos conceitos e categorias universais - que nos oferecem, não raras vezes, respostas prontas e demasiadamente simples - a fim de buscar, no interior dessas categorias, as especificidades da pessoa humana verdadeiramente concreta, com suas angústias e alegrias, próprias de sua existência singular. Esse exercício, esse movimento do ato hermenêutico, denominamos, no presente trabalho, "efeito matriosca", na medida em que vai desvendando, a partir do universal que está na superfície dos conceitos jurídicos aplicáveis à realidade, o detalhe do concreto, das circunstâncias do caso que, muitas

\footnotetext{
1 A lenda da Matrioska não se encerra neste ponto e tampouco tem um final feliz.
} 
vezes, se esconde de juristas a aplicadores do direito, seja porque não a percerbem adequadamente, seja porque julgam algo de menor importância.

Neste sentido, podemos observar que no campo próprio das relações jurídicas de consumo, marcadas pela massificação dos conflitos e das decisões judiciais, esses detalhes extraídos das circunstâncias do caso podem passar despercebidos pelo intérprete e aplicador do direito, embora sejam de extrema relevância, sobretudo em casos envolvendo pessoas humanas pertencentes a grupos sociais hipervulneráveis (crianças, idosos, superendividados, doentes, portadores de necessidades especiais etc.). Na superfície do Direito do Consumidor sabemos todos que o consumidor é uma categoria social vulnerável, que alcança a todos, pois todos somos consumidores. Nada mais universal e universalizante! Por detrás dessa categoria descortina-se outra, a dos grupos sociais em situação de vulnerabilidade agravada, os grupos hipervulneráveis; uma categoria mais específica do que a primeira, mas ainda assim universal, pois abarca todas as pessoas, sem distinção, que pertencem a esses grupos (todos os idosos, todas as crianças, todos os superendividados etc.). Contudo, nenhuma delas chega às especificidades do concreto, que apenas a análise da situação e o recurso a certos marcadores sociais de diferenças pode revelar².

Para a realização dos objetivos propostos, o presente trabalho - que pretende ser apenas um exercício de reflexão - será desenvolvido do seguinte modo: em primeiro lugar, será realizada uma análise da vulnerabilidade enquanto categoria mais universal do consumidor, demonstrando o quanto a ideia de sujeito vulnerável justifica a própria existência do sistema jurídico de proteção aos consumidores; em segundo lugar, será realizada análise da hipervulnerabilidade enquanto categoria universal, porém relacionada apenas a certos grupos na sociedade de consumo contemporânea; em terceiro lugar, será realizada análise da importância de uma interpretação jurídica que leve em conta as especificidades concretas do consumidor hipervulnerável e por fim, será feita uma reflexão a partir de uma leitura da jurisprudência brasileira - representada por certos julgados previamente selecionados nos

2 Assim, por exemplo, pode-se afirmar que toda criança é um consumidor hipervulnerável diante da publicidade infantil. Mas é possível afirmar que os efeitos deste tipo de publicidade refletem-se igualmente em crianças que pertencem a classe econômica A e aquelas que pertencem a classes economicamente menos favorecidas? 
Tribunais brasileiros - quanto à observância desse olhar atento às circunstâncias do caso envolvendo a pessoa humana enquanto consumidora hipervulnerável.

No aspecto metodológico, o artigo resulta de uma pesquisa predominantemente qualitativa, pautada basicamente pela revisão bibliográfica e documental (coleta de jurisprudência dos Tribunais brasileiros). O método de abordagem é o crítico-dialético, tendo com o enfoque a tensão entre o reconhecimento de condições universais de vulnerabilidade e hipervulnerabilidade e a necessidade de uma interpretação jurídica que, partindo dessas premissas universais, reconheça as especificidades concretas da pessoa humana consumidora e hipervulnerável em determinada situação real. De acordo com o método utilizado, aponta-se como uma das leis fundamentais a passagem da quantidade à qualidade ou mudança qualitativa (MARCONI; LAKATOS, 2017, p. 75).

\section{A SUPERFÍCIE DA MATRIOSCA - O CONSUMIDOR COMO PESSOA HUMANA VULNERÁ VEL NO MERCADO DE CONSUMO}

A relação de consumo é uma relação jurídica típica e sua tipicidade reside na diferença entre os sujeitos que a compõem, já que de um lado está o expert, que detém controle da informação a respeito dos produtos e serviços que oferta e do outro, o leigo, consumidor, que não possui esse controle e necessita confiar naquilo que o fornecedor lhe transmite (AZEVEDO, 2017, p. 238). Tal configuração revela um desequilíbrio estrutural, isto é, inerente à própria relação jurídica, resultando na necessidade de reconhecimento do consumidor como categoria social vulnerável ${ }^{3}$ e, por óbvio, na existência do próprio Direito do Consumidor.

3 A ideia (ou percepção) da vulnerabilidade, compreendida como uma qualidade própria do ser humano, representa a possibilidade de exposição a situações de sofrimento e de morte, seja em razão do meio social ou pela influência da própria natureza. A sujeito em condição vulnerável é, assim, uma vítima em potencial ou, como afirma Chazal (2000, p. 243), alguém que "peut être blessé" ("pode ser ferido"). Tal realidade, ao mesmo tempo em que é inerente a própria condição humana apresenta-se também como uma realidade relacional, isto é, diz respeito a fragilidade de alguém diante do poder dominante de outra pessoa em determinado contexto histórico-cultural, a exemplo das relações que se estabelecem entre consumidores e fornecedores no contexto da sociedade contemporânea de consumo. 
A origem do Direito do Consumidor no Brasil associa-se ao advento da Constituição Federal de 1988 que, em seu artigo 5, XXXII (BRASIL, 1988), identificou o consumidor como titular de direito e garantia fundamental de proteção jurídica nas relações de consumo por meio da atuação positiva do Estado. No dizer de Marques, um direito subjetivo público de natureza prestacional ou direito à prestação positiva do Estado (BENJAMIN et al, 2010, p. 31). Do mesmo modo, através do artigo 48 do Ato das Disposições Constitucionais Transitórias, determinou a edição de uma lei ordinária, um código para tornar plenamente eficaz o mandamento constitucional (BRASIL, 1988).

O Código de Defesa do Consumidor (BRASIL, 1990) surgiu como decorrência direta da vontade constituinte e, conforme artigo $1^{\circ}$ do referido diploma legal, suas normas de ordem pública e interesse social devem ser aplicadas sempre no sentido de proporcionar maior eficácia possível ao direito fundamental de proteção aos consumidores que, como os demais direitos fundamentais da pessoa humana, está associado ao princípio fundamental da dignidade da pessoa humana enquanto norma e valor fundamental da ordem jurídica, previsto no artigo $1^{\circ}$, III, da Constituição Federal (BRASIL, 1988).

Neste sentido, o primeiro passo é o reconhecimento do consumidor como sujeito pertencente a uma categoria social vulnerável, de acordo com o art. $4^{\circ}$, I do diploma consumerista (BRASIL, 1990), na medida em que essa condição, sendo mais do que uma presunção universal e absoluta de direito (iure et de iure), integra a própria definição jurídica de consumidor enquanto destinatário final de produtos e serviços (LOPES, 2005, p. 100). Com efeito, o reconhecimento jurídico da condição vulnerável a todo e qualquer consumidor decorre, em última instancia, do princípio fundamental a igualdade material ou substancial (AZEVEDO, 2017, p. 32-34), que confere direito fundamental a tratamento isonômico, isto é, ao tratamento que leva em conta as diferenças reais existentes entre determinados indivíduos e grupos sociais (BRASIL, 1988). Nas relações de consumo, significa dar tratamento diferenciado entre aqueles que ocupam a posição jurídica de vulnerabilidade e os que ocupam a posição dominante, de superioridade econômica e técnica (MIRAGEM, 2009, p. 222).

Isso tudo decorre da compreensão de que o consumidor não é apenas um contratante ou adquirente de produtos e serviços. Antes, e além disso, ele é o ente vulnerável da relação de consumo, uma categoria social reconhecida constitucionalmente na pessoa humana e na 
coletividade que integra a sociedade contemporânea de consumo e nela realiza efetivos atos de aquisição ou utilização de produtos e serviços como destinatário final, estando ainda exposta a práticas comerciais abusivas dos fornecedores ou sendo vítima de acidentes envolvendo produtos e serviços defeituosos postos no mercado de consumo (BRASIL, 1990).

$\mathrm{O}$ reconhecimento da vulnerabilidade dos consumidores decorre, segundo a doutrina francesa, de dois fatores específicos que são o econômico e o cognitivo ou informacional (CHAZAL, 2000, p. 247). E de fato, essas são as principais razões pelas quais se deve reconhecer a pessoa humana, de modo universal, como um sujeito vulnerável nas relações de consumo $^{4}$. A doutrina brasileira, por sua vez, realizou importantes desdobramentos desses fatores gerais apontados pelos franceses, sobretudo o cognitivo ou informacional (MARQUES, 2005, p. 320-334), resultando em uma vulnerabilidade fática, técnica, jurídica ou informacional (déficits de informação acerca de produtos e serviços, a respeito de direitos e instrumentos de tutela, bem como o excesso de informação e o perigo da exposição no mundo virtual).

Enfim, trata-se de uma condição universal na medida em que atinge a todas as pessoas humanas inseridas na sociedade contemporânea, que tem no consumo o principal fator de realização pessoal diante das perplexidades e dos grandes vazios existenciais suportados pelo Homo consumericus (LIPOVETSKY, 2007, p. 44-45). Uma conformação que atinge a todos, pois ainda que se possa estabelecer níveis distintos de acesso ao consumo em uma sociedade pluralist $^{5}$, todos somos, de fato, consumidores, ainda que apenas dos serviços essenciais e vitais ao mínimo existencial humano.

Essa percepção, absolutamente visível ao jurista e aplicador do direito, está na superfície da Matriosca. Contudo, revela-se insuficiente na medida em que todos os consumidores são vulneráveis mas nem todos possuem, de fato, os mesmos níveis de vulnerabilidade. É necessário "abrir a boneca” para desvendar o que se esconde, afinal, por

\footnotetext{
4 É importante lembrar que o direito brasileiro confere também às pessoas jurídicas a possibilidade de serem enquadradas na categoria universal vulnerável, isto é, na categoria consumidora, desde que atuem como destinatários finais de produtos e serviços, conforme prevê o art. $2^{\circ}$ do CDC (BRASIL,1990). Contudo, o presente artigo centra a sua atenção no consumidor enquanto pessoa humana.

5 No sentido de que a categoria universal consumidora é heterogênea, formada por variados grupos sociais identificados por distintos marcadores sociais, como sexo, gênero, idade, renda etc.
} 
debaixo da superfície: uma segunda realidade universal, porém relacionada a determinados grupos de consumidores com níveis mais elevados de vulnerabilidade, os grupos hipervulneráveis.

\section{A SEGUNDA CAMAdA DA MATRIOSCA: A PESSOA HUMANA SITUADA EM GRUPO UNIVERSAL HIPERVULNERÁVEL.}

A condição hipervulnerável das pessoas humanas situadas em certos grupos sociais de consumidores decorre igualmente do princípio fundamental à igualdade material ou substancial (AZEVEDO, 2017, p. 32-34), mas agora a aplicação do direito ao tratamento isonômico se dá entre os próprios vulneráveis da relação de consumo, como exigência de justiça social (AZEVEDO, 2012, p. 16-21). Trata-se de reconhecer que, em razão da natureza heterogênea da categoria social consumidora, há pessoas humanas em situação de maior vulnerabilidade do que o modelo padrão de consumidor. Esse agravamento da condição vulnerável, que pode ocorrer por alguma circunstância permanente ou temporária (MARQUES et al., 2012, p. 189), exige do jurista e aplicador do direito o "pequeno esforço" de abrir a Matriosca, de sair da superfície da condição universal vulnerável para enxergar o que há por detrás dela, situação que felizmente acabou ocorrendo pela sensibilidade do Judiciário.

Há pelo menos uma década a jurisprudência brasileira, sobretudo a do STJ, vem reconhecendo a necessidade de dar tratamento jurídico qualificado a determinados grupos sociais em situação de hipervulnerabilidade, utilizando-se expressamente desta terminologia ${ }^{6}$. Desde então, é possível encontrar decisões no STJ e nos Tribunais de Justiça a respeito do reconhecimento desta "subcategoria universal" dos vulneráveis, isto é, a categoria universal dos grupos hipervulneráveis, cujos critérios de pertencimento não são absolutos, mas extraídos, de modo exemplificativo, da adequada interpretação ao artigo 39, IV do CDC (BRASIL, 1990). Em outros termos, os hipervulneráveis seriam aqueles que, em razão de sua "idade, saúde, conhecimento e condição social" possuem maior dificuldade de fazer frente à

6 Neste sentido, uma das decisões pioneiras, da lavra do Min. Herman Benjamin, no REsp 586.316 MG, j. 17.04.2007.

Rev. de Direito, Globalização e Responsabilidade nas Relações de Consumo | e-ISSN: 2526-0030 | Porto Alegre | v. 4 | n. 2 | p. $88-107$ | Jul/Dez. 2018 
posição dominante dos fornecedores e se encontram em posição de maior risco quanto a danos patrimoniais e existenciais. Os critérios indicados no dispositivo legal do CDC seriam exemplificativos, porque não incluiriam apenas os hipervulneráveis reconhecidos na Constituição Federal de 1988, tais como os portadores de deficiência, os idosos, as crianças e os adolescentes, alcançando ainda outros grupos, como o dos doentes, dos superendividados etc. (MARQUES et al., 2012, p. 189) ${ }^{7}$.

Neste sentido, é importante observar que a finalidade maior desse reconhecimento jurídico, a eficácia do mandamento constitucional referente ao direito e garantia fundamental de proteção ao consumidor para a promoção da dignidade da pessoa humana no mercado de consumo (BRASIL, 1988), depende, em larga medida, da capacidade do intérprete a aplicador do direito manejar o sistema jurídico em perspectiva de um "diálogo sistemático e simultâneo" entre as fontes legais do sistema jurídico, tais como o CDC e o Código Civil, o CDC e os Estatutos do Idoso, da Criança e do Adolescente, da Pessoa Portadora de Deficiência etc (MIRAGEM, 2012, p. 95-109).

O reconhecimento da condição hipervulnerável de certos grupos de consumidores é, de fato, um grande avanço em nossa doutrina e jurisprudência brasileiras. Contudo, é necessário não perder de vista que os grupos são ainda categorias universais. Assim, toda criança, todo idoso, todo portador de necessidades especiais são hipervulneráveis! Mas entre tais grupos podem haver diferenças importantes, que certos marcadores sociais podem indicar em uma pesquisa mais aprofundada ${ }^{8}$, bem como as circunstâncias de determinado caso concreto.

\section{A TERCEIRA CAMADA DA MATRIOSCA: AS ESPECIFICIDADES CONCRETAS DO CONSUMIDOR HIPERVULNERÁVEL.}

No interior dos grupos sociais que compõem a categoria universal hipervulnerável nas relações de consumo escondem-se certas especificidades que só podem ser descobertas por

7 E há ainda aqueles em situação de uma quase "invisibilidade social”, como, por exemplo, a população refugiada ou migrante, para quem o próprio mercado de consumo em regra não se dirige.

8 Assim, por exemplo, o marcador social de renda pode revelar muito sobre as diferenças entre os idosos ou as crianças enquanto hipervulneráveis.

Rev. de Direito, Globalização e Responsabilidade nas Relações de Consumo | e-ISSN: 2526-0030 | Porto Alegre | v. 4 | n. 2 | p. $88-107$ | Jul/Dez. 2018 
meio de pesquisas acadêmicas que apontem para determinados marcadores sociais de diferenças ou ainda na interpretação judicial a partir da análise de determinado caso concreto.

Assim, é fundamental que se reconheçam as diferenças existentes no interior dos grupos sociais hipervulneráveis, tais como o das crianças e dos adolescentes, dos idosos, dos portadores de necessidades especiais, dos superendividados e isso porque o tratamento universal dispensado a todos os hipervulneráveis acaba desconsiderando fatores importantes que dizem respeito ao pertencimento das pessoas humanas a realidades muito específicas, ditadas pela renda econômica, pelo comportamento relacionado a sua condição de sexo e gênero, por condição racial dentre outras. Neste aspecto, a pesquisa acadêmica, sobretudo a que se desenvolve dentro um viés empírico, é de extrema importância para revelar esses dados que, como dito antes, não são perceptíveis ou se mostram desimportantes para o mundo jurídico, preferindo-se a "comodidade" das categorias universais ${ }^{9}$.

No campo da decisão judicial, que se depara com a concretude da situação real, vivida e experimentada por uma pessoa humana consumidora, há também espaço para ir além da categoria universal hipervulnerável e verificar, com olhar atento e sensível, a existência desses marcadores sociais que a academia já se propõe desvendar.

\section{UMA LEITURA DA JURISPRUDÊNCIA BRASILEIRA A PARTIR DAS ESPECIFIDADES CONCRETAS DO CONSUMIDOR HIPERVULNERÁVEL.}

A hipervulnerabilidade é a situação que foi reconhecida jurisprudencialmente no

Direito Brasileiro como um estado de vulnerabilidade acentuado e específico, de extrema

\footnotetext{
9 Em pesquisa ao catálogo de teses e dissertações da CAPES, com os descritores "consumo" e "marcadores sociais de diferença" foram encontrados muitos trabalhos interessantes, a maioria relacionados às áreas de Antropologia Social e Propaganda e Marketing. De modo exemplificativo, destacamos os seguintes: a)MACEDO, Renata Guedes Mourão.Espelho mágico: empregadas domésticas, consumo e mídia. 14/08/2013 247 f. Mestrado em CIÊNCIA SOCIAL (ANTROPOLOGIA SOCIAL) Instituição de Ensino: UNIVERSIDADE DE SÃO PAULO, São Paulo Biblioteca Depositária: FFLCH/USP, b) SANTOS, Luis Henrique dos. ESTEREÓTIPOS E CONSUMO: Estratégias da Produção do Discurso da Diferença na Comunicação Publicitária' 01/03/2012 205 f. Mestrado em COMUNICAÇÃO E PRÁTICAS DE CONSUMO Instituição de Ensino: ESCOLA SUPERIOR DE PROPAGANDA E MARKETING, SÃO PAULO Biblioteca Depositária: Biblioteca Central Napoleão de Carvalho.
} 
fragilidade de determinados grupos sociais, que se reflete especialmente nas relações com indíviduos ou grupos em posição jurídica dominante, isto é, mais forte.

Assim, entende-se que a hipervulnerabilidade é uma situação fática e objetiva de agravamento da vulnerabilidade da pessoa física consumidora, em razão de características pessoais aparentes ou conhecidas pelo fornecedor, enquadrando-se aí consumidores crianças, idosos, enfermos, deficientes físicos, analfabetos, dentre outros.

O reconhecimento da definição acima apontada segue:

A hipervulnerabilidade seria a situação social fática e objetiva de agravamento da vulnerabilidade da pessoa física consumidora, por circunstâncias pessoais aparentes ou conhecidas do fornecedor, como sua idade reduzida (assim, o caso da comida para bebês ou da publicidade para crianças) ou idade alentada (assim, os cuidados especiais com os idosos, tanto no Código em diálogo com o Estatuto do Idoso e da publicidade de crédito para idosos) ou sua situação de doente (assim caso do glúten e sobre informações na bula de remédios)(MARQUES; MIRAGEM, 2012, p. 185).

Nesse sentido, a vulnerabilidade tida hoje como princípio, é presumível e inerente a todos os consumidores, a condição mais universal da categoria social consumidora. Já a hipervulnerabilidade, condição universal mais vinculada a determinados grupos sociais, é situação advinda do conceito de igualdade, servindo às situações especiais pelas quais se encontra um consumidor, temporariamente (gravidez, doença passageira, analfabetistmo, idade, etc), ou permanentemente (incapacidade, deficiência física ou mental, etc) (MARQUES; MIRAGEM, 2012, p. 185).

A condição hipervulnerável em exame surgiu reconhecida primeiramente com viés social. Dessa maneira, de acordo com a jurisprudência do STJ, o voto do Ministro Relator Desembargador Herman Benjamin no REsp n ${ }^{\circ}$ 931513/RS, julgado no ano de 2009 explicou de maneira muito clara a condição de sujeitos portadores de necessidades especiais que se encontravam em situação de hipervulnerabilidade, garantindo-lhes o amplo acesso à justiça. Com a devida vênia transcreve-se trechos do voto do respeitável Relator:

[...]A categoria ético-política, e também jurídica, dos sujeitos vulneráveis inclui um subgrupo de sujeitos hipervulneráveis, entre os quais se destacam, por razões óbvias, as pessoas com deficiência física, sensorial ou mental.

[...]Ao se proteger o hipervulnerável, a rigor quem verdadeiramente acaba beneficiada é a própria sociedade, porquanto espera o respeito ao pacto coletivo 
de inclusão social imperativa, que lhe é caro, não por sua faceta patrimonial, mais precisamente por abraçar a dimensão intangível e humanista dos princípios da dignidade da pessoa humana e da solidariedade [...]

O ilustre relator alicerçou a proteção aos sujeitos hipervulneráveis, primeiramente pela questão econômica, no sentido de que as pessoas portadoras de necessidades especiais se acham, infelizmente, em estado de improdutividade e em razão disso, acabam sofrendo barreiras de inclusão social, tendo, inclusive, de ser mantidas por outros contribuintes. Outro aspecto valorado foi a isonomia, primando pelo tratamento especial em virtude da valorização da isonomia material e não de forma, assegurando-se, portanto, a igualdade perante a lei.

O terceiro e último aspecto inicial esclarecedor da necessidade do reconhecimento da hipervulnerabilidade no acórdão proferido foi o plano moral, levando-se em consideração o aspecto histórico de uma sociedade que preferiu sempre esconder e imolar ao invés de incluir respeitando as necessidades e limitações das pessoas mais necessitadas.

Pode-se dizer, portanto, que a base de criação dos estudos da hipervulnerabilidade foi esculpida no princípio da dignidade de pessoa humana, mostrando-se veemente que não haja, principalmente, discriminação aos grupos reconhecidamente como hipervulneráveis, pois em condição de fragilidade acentuada.

A jurisprudência dos nossos tribunais superiores vêm trazendo inúmeros casos de reconhecimento da hipervulnerabilidade nas relações de consumo. Pode-se citar o emblemático caso da promessa de cura da doença do câncer oferecida pelo produto denominado cogumelo do sol. No caso relatado, os nobres julgadores primaram por considerar a propaganda enganosa com o intuito de induzir em erro o consumidor fragilizado, havendo uma potencialidade na vulnerabilidade, a hipervulnerabilidade. Assim, segue a ementa do Recurso Especial:

RECURSO ESPECIAL. DIREITO DO CONSUMIDOR. AÇÃO INDENIZATÓRIA. PROPAGANDA ENGANOSA. COGUMELO DO SOL. CURA DO CÂNCER. ABUSO DE DIREITO. ART. 39, INCISO IV, DO CDC. HIPERVULNERABILIDADE. RESPONSABILIDADE OBJETIVA. DANOS MORAIS. INDENIZAÇÃO DEVIDA.DISSÍDIO JURISPRUDENCIAL 
No referido acórdão, invocou-se a publicidade abusiva, contida no art. $37, \S 2^{\circ}$ do CDC (BRASIL, 1990), principalmente pois explora o medo ou a superstição de um pai que busca a cura do filho menor de idade acometido de doença gravíssima, como o câncer. Nesse caso, o pai do menino buscou o medicamento cogumelo do sol para tentar combater um câncer que acometia a criança no fígado em estado avançado. A medicação foi adquirida em 1999, mas infelizmente o menino veio a óbito em 2002, três anos depois.

Foi abordado que o produto cogumelo do sol foi vendido ao pai do menino sob a garantia de cura da doença, passando a afirmação de que atuaria no sistema imunológico, de maneira a reduzir as células cancerígenas. Não restou qualquer dúvida quanto à indução em erro a qual passou o autor da ação, sendo destacada a maneira pouco profunda com relação à informação de que se trata de um alimento e não um medicamento, ademais porque não era registrado como tal. Interessante referir que o tribunal de origem, apesar de considerar enganosa a publicidade a que o autor foi submetido, considerou o fato como um mero dissabor do cotidiano, não havendo ofensa à personalidade depois de três anos de uso e da continuidade do tratamento, reformando a sentença de primeiro grau, não concedendo os danos morais.

Já o Egrégio Superior Tribunal de Justiça explorou o artigo 31 do Código de Defesa do Consumidor (BRASIL, 1990) sob a necessidade de informações claras, ostensivas, seguras sobre qualidades e riscos do produto oferecido ao consumidor. Assim, a oferta publicitária enganosa e abusiva gerou no consumidor falsas expectativas que perpassaram meros dissabores, eis que se aproveitou da situação de hipervulnerabilidade do consumidor, cuja dignidade primou-se por preservar no caso concreto.

Nesse caso, a hipervulnerabilidade do consumidor restou configurada pois estava abalado pela agressividade da doença que acometia seu filho, destacando-se, o intuito de lucro, situação vil perante à triste situação vivenciada. A própria decisão enfatizou a hipervulnerabilidade do pai do menino em razão da vulnerabilidade informacional potencializada ou agravada, bem como comparou a conduta de indução ao erro do consumidor em si com o estado de perigo, previsto no artigo 156 do Código Civil 
(BRASIL, 2002). A indenização por danos morais foi reconhecida justamente pela incoerência das informações prestadas à vítima, aliado ao seu estado pessoal, o que gerou maiores angústias no consumidor e, nesse caso, prescindível de demonstração de prejuízo, sendo considerado in re ipsa.

Ainda sobre o caso, a ré, empresa que comercializava o produto "milagroso" para a cura do câncer, foi condenada criminalmente com incurso no artigo 283 do código penal (BRASIL, 1940) por anunciar cura através de meio infalível, o que agravou por demais a situação concreta. Por fim, cabe consignar que o consumidor lesado obteve indenização por danos morais no montante de $\mathrm{R} \$ 30.000,00$ (trinta mil reais), de acordo com os parâmetros estabelecidos pelo STJ.

Em mais um acórdão originário do Tribunal de Justiça do Rio Grande do Sul, encontramos excelente decisão proferida em caso de concessão de crédito consignado a pessoa idosa. Em análise da referida situação, vislumbrou-se tratar de pessoa idosa que foi ludibriada por uma sobrinha, a qual manejou instrumentos para obter empréstimo consignado na conta da idosa sob aceitação do banco, sem a exigência de instrumento público para perfectibilizar a contratação do crédito. Vejamos:

Ementa: CONTRATO BANCÁRIO. NULIDADE DO CONTRATO
DE CRÉDITO CONSIGNADO.
IDOSO:HIPERVULNERABILIDADE AGRAVADA PELA SURDEZ E O
ANALFABETISMO. IMPRESSÃO DIGITAL E ASSINATURA A ROGO
COMO CAUSAS CONCORRENTES DA NULIDADE.
IMPRESCINDIBILIDADE DE INSTRUMENTO PÚBLICO. DANO MORAL:
A PRÁTICA DE UM ATO POR PARTE DO BANCO, QUE O CDC
QUALIFICA COMO "ABUSIVO", QUAL O DE APROVEITAR-SE DA
FRAGILIDADE DO IDOSO, IMPLICA, POR INFERÊNCIA LÓGICA, QUE
HOUVE LESÃO TAMBÉM AO ESTATUTO DO IDOSO. APROVEITAR-SE
DAS SUAS VISÍVEIS FRAGILIDADES MATERIALIZA VIOLAÇÃO AO
CDC E À REGRA DO RESPEITO À SENECTUDE. DEVOLUÇÃO
CORRIGIDA DAS PARCELAS DESCONTADAS. PROVIDO O RECURSO.
(Apelação Cível No 70059723601, Vigésima Terceira Câmara Cível, Tribunal
de Justiça do RS, Relator: Ana Paula Dalbosco, Julgado em 16/12/2014)

É interesse da proteção ao consumidor a questão envolvendo o reconhecimento da hipervulnerabilidade em relação à pessoa idosa frente à contratação de um contrato de crédito consignado perante uma instituição financeira. 
Foi identificado pela douta relatora na decisão supracitada que apesar de haver a proteção da pessoa idosa, já reconhecida pela doutrina e pela jurisprudência como parte hipervulnerável na relação de consumo, admitindo que assim se dá pela própria fragilidade da condição humana na idade madura frente ao avanço da ciência e da alta complexidade das relações negociais, em consonância com a proteção conferida pelo Estatuto do Idoso, Lei $\mathrm{n}^{\circ}$ 10.741/2003, a legislação ordinária, através da Lei no 10.820/2003, permitiu a contratação de crédito consignado, sendo considerado um nicho mercadológico destinado ao consumidor idoso, já que promete a contratação de empréstimos a juros reduzidos com desconto em folha de pagamento para os trabalhadores ou direto do benefício previdenciário, que é o caso de aposentados ou pensionistas.

O entendimento relatado na decisão primou pela proteção dos consumidores hipervulneráveis e melhor visão não poderia haver.

O caso acima tratou de uma pessoa idosa com 80 (oitenta) anos de idade, que não sabia ler e escrever e além de tudo isso portadora de uma necessidade especial, a surdez.

Some-se às condições da idosa descritas acima foi relatado no acórdão as dificuldades de entendimento da vítima quanto ao conteúdo dos contratos de consignação.

A instituição financeira agiu em total abuso perante a consumidora pois permitiu que uma sobrinha sua, sem instrumento de procuração firmasse um dos três contratos de consignação que lhe descontava a importância de R\$ 20,60 (vinte reais e sessenta centavos) ao mês.

Foi aventado também, apesar de não considerado que havia uma aposição digital no contrato o que, se levado à efeito, segundo a relatora, seria bem pior para o banco demandado pois comprovaria cabalmente que tinha conhecimento da situação de fragilidade do analfabetismo da autora pois sequer conseguia desenhar sua assinatura.

Um dos registros que merece consideração da ilustre relatora foi aquele que apontou que apesar de ser pessoa capaz, a forma pela qual se deu a negociação não estava prescrita em 
lei, tendo em vista que ato exigiria a atuação mediante procuração por instrumento público para que sua sobrinha pudesse contratar em nome da autora.

É importante mencionar que a oferta do crédito consigando através de vantagens, simplificações e facilidades, demonstra instrumento ardil diante da falta de preparo e conhecimento dos consumidores hipervulneráveis, como é o caso do acórdão. Além de portadora de necessidade especial, qual seja a surdez, era uma pessoa analfabeta e idosa.

A análise da situação sob a tríplice vulnerabilidade exacerbada da contratante do crédito consignado.

Além de tudo isso, há que considerar-se o superendividamento aventado no acórdão. No caso, uma pessoa com pensionamento de $\mathrm{R} \$ 830,00$ (oitocentos e trinta reais) mensais se vê diante de três empréstimos e recebendo a quantia líquida de $\mathrm{R} \$ 491,00$ (quatrocentos e noventa e um reais). Além disso, o fato de ser analfabeta e portadora de surdez fez com que o nobre julgador tecesse comentários pertinentes no sentido de que, apesar de haver uma impressão digital no processo com a aposição da autora, ainda que o contrato tenha sido lido a ela, lhe falta a condição de ouvir, o que agrava sobremaneira o caso, vislumbrando-se flagrante atentado ao art.39, IV do CDC (BRASIL, 1990).

Outro caso marcante e que jamais poderia ser olvidado é aquele que diz respeito ao reconhecimento de dano moral reflexo a uma mãe que passa pela angústia de ver seu filho internado em decorrência da utilização inadequada de um toboágua em um clube recreativo que não teve o devido monitoramento. Assim:

Ementa: APELAÇÃO CÍVEL - AÇÃO DE REPARAÇÃO DE DANOS ACIDENTE EM CLUBE RECREATIVO - UTILIZAÇÃO INADEQUADA DE TOBOÁGUA - INTERNAÇÃO DO MENOR EM CTI SOFRIMENTO E ANGÚSTIA DA GENITORA - RESPONSABILIDADE CIVIL - DANO MORAL REFLEXO OU POR RICOCHETE - PEDIDO PROCEDENTE - QUANTUM. - É obrigação de um clube recreativo zelar pela segurança dos usuários que se utilizam de suas dependências, especialmente para as crianças que usufruem dos brinquedos que exigem rigor e monitoramento na utilização. O resultado lesivo comprova que o clube foi negligente no monitoramento da criança que se acidenta no toboágua, sofrendo grave lesão de abdome pela utilização concomitante de outro usuário, ferindo a integridade física do menor. - É presumido o dano moral do genitor em virtude de grave acidente ocorrido com seu filho menor nas dependências de clube recreativo, exigindo a internação da criança em CTI por vários dias, devendo o 
'quantum' indenizatório ser fixado atentando-se para as condições das partes, a gravidade da lesão e as circunstâncias fáticas, não se podendo ainda olvidar a repercussão na esfera do lesado e o potencial econômico-social do ofensor.(TJMG - Apelação Cível AC 10024102309754001 Data de publicação: $11 / 04 / 2014)$

A referida apelação foi julgada em 2014 e expõe a realidade da mãe de uma criança, consumidora de um clube recreativo que utilizava das benesses dele, dentre eles um toboágua.

O menino vítima do acidente contava com 09 (nove) anos de idade e ao descer no toboágua em direção a uma das piscinas veio a colidir com outro usuário que também estava descendo, sendo atingido na região do abdome, o que levou o menino a ser internado necessitando de CTI pediátrica.

Nesse caso, quem buscou a justiça foi a mãe do menino, a qual alegou estar abalada moralmente pela situação que levou seu filho até a internação (sofrimento e angústia).

Restou comprovado nos autos que não havia qualquer fiscalização quando da utilização do toboágua pelo menino de 09 anos, o qual foi atingido por um adulto, sendo por isso reconhecida a negligência do clube quanto aos usuários.

$\mathrm{O}$ dano moral foi reconhecido à mãe do menino e autora da ação como verdadeiro exercício de um direito próprio, levando em consideração o sofrimento demasiado pelo qual passou a ver seu filho internado em situação de gravidade em uma CTI em razão do acidente, além do receito de que o quadro de saúde piorasse. Tal dano por ricochete teve sua extensão limitada para que não desencadeasse uma sucessão de responsabilização indefinida.

O caso retrata a hipervulnerabilidade da mãe em relação ao filho, justamente a situação do art.39, IV do CDC (BRASIL, 1990). Evidencia-se como especificidade concreta a hipervulnerabilidade do núcleo familiar, primeiro a criança e em decorrência da situação pela qual passou a sua mãe, diretamente "atingida" pelo sofrimento de seu filho, que lhe ocasionou mais sofrimento ainda.

Diante disso, demonstra-se que a jurisprudência dos Tribunais Superiores e dos Tribunais de Justiça tem trazido importante contribuição em favor dos grupos sociais 
hipervulneráveis. E em determinados julgados, ainda que em grau superior, é possível encontrar a presença do olhar atento a determinadas especificidades concretas da pessoa consumidora, chegando assim a "camada mais interna da Matriosca". O olhar que vê, em detalhes próprios das circunstâncias do caso, elementos fundamentais para uma decisão judicial verdadeiramente justa na medida em que concretiza os princípios da igualdade material (isonomia) e da dignidade da pessoa humana nas relações de consumo.

\section{CONCLUSÕES}

De todo o exposto conclui-se no sentido de que a reconhecimento jurídico da vulnerabilidade como condição universal de todo consumidor (BRASIL, 1990) é um dos grandes marcos do direito privado contemporâneo, permitindo a realização da isonomia a todos os consumidores em suas relações com os fornecedores de produtos e serviços. Não fosse por esse reconhecimento, consequência direta da figura do consumidor enquanto sujeito de direitos fundamentais, pela disposição do art. $5^{\circ}$, XXXII da Constituição Brasileira (BRASIL, 1988), os consumidores não teriam a necessária proteção jurídica e estariam absolutamente desamparados no mercado de consumo, marcado pelo desequilíbrio estrutural de forças entre os seus sujeitos.

A condição universal vulnerável do consumidor - inclusive as pessoas jurídicas, enquanto destinatárias finais de produtos e serviços - permitiu a construção de um rico repertório jurisprudencial em favor dos consumidores expostos a uma infinidade de práticas comerciais abusivas, a contratos leoninos e a danos causados por produtos e serviços defeituosos ou com vícios de inadequação; a publicidade enganosa e abusiva; a utilização indevida da cobrança de dívidas e dos bancos de dados e cadastros dos consumidores. Ao longo dos anos 90 e da primeira década dos anos 2000, permitiu ainda a utilização das ações revisionais contratuais com fundamento na lesão objetiva e na onerosidade excessiva superveniente da prestação. Tudo em favor de todo e qualquer consumidor. Esse primeiro marco está na superfície da Matriosca.

Contudo, o segundo marco surgiu com a identificação e consagração dos grupos hipervulneráveis de consumidores, outra conquista importante para o direito privado 
contemporâneo na busca de realização da igualdade e da dignidade humana. Agora se trata de reconhecer que se todos são consumidores e, portanto, vulneráveis diante dos fornecedores, nem todos os consumidores são iguais, nem todos têm o mesmo grau de vulnerabilidade! Os grupos hipervulneráveis também são universais, na medida em que todos os idosos, todos as crianças, todos os doentes, todos os portadores de necessidades especiais etc. encontram-se agora dentro dessa condição, integram essa segunda categoria social consumidora. Esse segundo marco é a segunda camada da Matriosca, encontra-se por trás da categoria universal vulnerável.

Se o olhar se volta, porém, para o que está "escondido" por detrás da condição universal hipervulnerável é possível perceber, no campo teórico-acadêmico e também no da decisão judicial, que há especificidades concretas da pessoa consumidora hipevulnerável, identificadas pelo pertencimento a determinados marcadores sociais de diferença (um idoso branco ou negro, que possui determinada renda, que é hetero ou homosexual etc.). Neste sentido, entende-se que a produção acadêmica, sobretudo a que provém de áreas afins ao campo jurídico, tem muito a contribuir com a aplicação do direito no campo jurisdicional, auxiliando juristas e operadores do direito a refinar o seu olhar para tais especificidades a partir das circunstâncias do caso.

Por fim, a análise de determinados julgados em nossa jurisprudência revela, em alguns momentos, esse exercício de refinamento do seu olhar para as especificidades concretas da pessoa humana hipervulnerável nas relações de consumo. Entende-se que esse olhar diferenciado, a medida em que evolui desde a primeira instância de julgamento, permite a construção de uma jurisprudência mais adequada à realização da defesa do consumidor enquanto direito fundamental da pessoa humana. 


\section{REFERÊNCIAS}

AZEVEDO, Fernando Costa de. O direito do consumidor e seus princípios fundamentais. Revista Eletrônica da Faculdade de Direito de Pelotas (UFPel). Dossiê Consumo e Vulnerabilidade: a proteção jurídica dos consumidores no século XXI. Vol. 03, N. 1, Jan-Jun., 2017.

Disponível

em:

<https://periodicos.ufpel.edu.br/ojs2/index.php/revistadireito/article/view/11960/7575>.

Acesso em 15.07.2018.

- O reconhecimento jurídico da hipervulnerabilidadede certos grupos de consumidores como expressão de um sentido material de justiça no contexto da sociedade de consumo contemporânea. I Seminário Internacional Imagens da Justiça, Currículo e Educação Jurídica (Anais). Pelotas: UFPel. 2012. Disponível em: <https://wp.ufpel.edu.br/imagensdajustica/>. Acesso em 10.03.2018.

Publicidad y relación jurídica de consumo. Breves reflexiones a partir del derecho brasileño. In ALVAREZ, Cesar Carranza. Temas Actuales del Derecho del Consumidor. Lima Normas Juridicas Ediciones.

BENJAMIN, Antonio Herman e Vasconcellos MARQUES, Claudia Lima BESSA, Leonardo Roscoe. Manual de Direito do Consumidor. 3. ed. São Paulo Revista dos Tribunais. 2010.

BRASIL. Código Civil. Lei $\mathrm{n}^{\mathrm{o}}$ 10.406, de 10 de janeiro de 2002.Disponível em:<http://www.planalto.gov.br/ccivil_03/leis/2002/110406.htm>. Acesso em 03.08.2018.

BRASIL. Código de Defesa do Consumidor. Lei $\mathrm{n}^{\circ}$ 8.078, de 11 de setembro de 1990.Disponível em: <http://www.planalto.gov.br/ccivil_03/leis/L8078.htm>. Acesso em 03.08.2018.

BRASIL. Constituição da República Federativa do Brasil de 1988. 16 ed. São Paulo: Saraiva, 2015.

BRASIL. TJ-MG Apelação Cível AC 10024102309754001. Data de publicação: 11/04/2014.

Disponível em: https://www.jusbrasil.com.br/jurisprudencia/busca?q=Sofrimento+e+ang\%C3\%BAstia\&yStar $\mathrm{t}=2018$. Acesso em 03.08.2018.

BRASIL.STJ. REsp 1329556 / SP RECURSO ESPECIAL 2012/0124047-6. Rel Min. Ricardo Villas Bôas Cueva. Data do Julgamento: 25/11/2014. Disponível em: <https://stj.jusbrasil.com.br/jurisprudencia/157527150/recurso-especial-resp-1329556-sp2012-0124047-6>. Acesso em 03.08.2018. 
Fernando Costa Azevedo \& Lúcia Dal Molin Oliveira

BRASIL. STJ. REsp no 931513/RS, 2007/0045162-7, Relator: Ministro CARLOS FERNANDO MATHIAS, Data de Julgamento: 25/11/2009, S1. Disponível em: < stj.jusbrasil.com.br/jurisprudencia/16804625/recurso-especial-resp-931513-rs-2007-

0045162-7-stj/voto-16804628>. Acesso em 03.08.2018.

BRASIL. TJ/RS. Apelação Cível No 70059723601, Vigésima Terceira Câmara Cível, Relator: Ana Paula Dalbosco, Julgado em 16/12/2014. Disponível em:< http://www.tjrs.jus.br $>$. Acesso em: 03.08.2018.

CHAZAL, Jean-Pascal. Vulnerabilité et droit de la consommation. In COHET-CORDEY, Frédérique. Vulnerabilité et droit. Le développement de la vulnérabilité et ses enjeux en droit. Presses Universitaires de Grenoble. 2000.

CORDEIRO, Isadora. A Lenda da Matrioska - A boneca russa. Disponível em: <https://isadoracln.wordpress.com/2011/06/09/a-lenda-da-matrioska-a-boneca-russa/>. Acesso em 29.07.2018.

LIPOVETSKY, Gilles. A felicidade paradoxal. Ensaio sobre a sociedade do hiperconsumo. Trad. Maria Lucia Machado. São Paulo: Companhia das Letras. 2007.

LOPES, José Reinaldo de Lima. Direito Civil e Direito do Consumidor - Princípios. In: PFEIFFER, Roberto A. C., PASQUALOTTO, Adalberto. Código de Defesa do Consumidor e o Código Civil de 2002. Convergências e assimetrias. São Paulo: Revista dos Tribunais. 2005.

MARCONI, Marina de Andrade; LAKATOS, Eva Maria. Metodologia científica. São Paulo: Atlas, 2017.

MARQUES, Claudia Lima. Contratos no Código de Defesa do Consumidor. 5. ed. São Paulo: Revista dos Tribunais. 2005.

MARQUES, Claudia Lima, MIRAGEM, Bruno. O novo direito privado e a proteção dos vulneráveis. 1 ed. São Paulo: Revista dos Tribunais. 2012.

MIRAGEM, Bruno. Abuso do Direito. Proteção da Confiança e Limite ao Exercício das Prerrogativas Jurídicas no Direito Privado. 1. ed. Rio de Janeiro: Forense. 2009.

Eppur si muove: diálogo das fontes como método de interpretação sistemática no direito brasileiro. In: MARQUES, Claudia Lima (Coord.). Diálogo das Fontes. Do conflito a coordenação de normas do direito brasileiro. São Paulo: Revista dos Tribunais. 2012. 